\title{
Qualidade de vida: Interpretação da sintaxe do SPSS para análise de dados do WHOQOL-100
}

\section{Quality of life: interpreting SPSS's syntax for analysing WHOQOL-100 data}

Celso Bilynkievycz dos Santos ${ }^{1,2,3}$, Bruno Pedroso $^{1,4}$, Luciano Scandelari $^{1}$ e Luiz A. Pilatti ${ }^{1}$

1 Universidade Tecnológica Federal do Paraná (UTFPR), Ponta Grossa - Paraná, Brasil. bilynkievycz@uepg.br, bilynkievycz@globo.com, brunops3@brturbo.com.br, py5kd@ onda.com.br, lapilatti@utfpr.edu.br

2 Universidade Estadual de Ponta Grossa (UEPG). Ponta Grossa - Paraná, Brasil

3 Centro Universitário Claretirano (CEUCLAR), Batatais - São Paulo, Brasil

4 Faculdades Integradas de Itararé (FAFIT-FACIC) Itararé - São Paulo, Brasil

Recebido em 26 Fevereiro 2009/Enviado para Modificação em 15 Agosto 2009/Aprovado 17 Setembro 2009

\section{RESUMO}

O presente trabalho descreve os comandos da sintaxe do software Statistical Package for the Social Sciences (SPSS) para análise dos dados do WHOQOL-100. Concluise que o entendimento da sintaxe constitui um fator limitante para a utilização do WHOQOL-100, e, também, que a análise parcial ou completa de dados do instrumento em exame pode ser realizada através de outros softwares.

Palavras-Chave: Qualidade de vida, questionários; análise de dados (fonte: DeCS, BIREME).

\section{ABSTRACT}

This study describes the Statistical Package for Social Sciences' (SPSS) syntax commands for analysing WHOQOL-100 data. It was concluded that understanding syntax is a factor limiting WHOQOL-100 use. Analysing partial or complete WHOQOL-100 data can be accomplished by other software.

Key Words: Quality of life, questionnaire, data analysis (source: MeSH, NLM).

RESUMEN

Calidad de vida: interpretación de la sintaxis del SPSS para el análisis de datos del WHOQOL-100

Se describen los comandos de sintaxis del Paquete Estadístico para Ciencias Sociales (SPSS) para el análisis del WHOQOL-100. Se concluye que la comprensión de la 
sintaxis es un factor que limita el uso del WHOQOL-100. El análisis de los datos parciales o completos puede llevarse a cabo por medio de otros programas.

Palabras Clave: Calidad de vida, cuestionarios, análisis de datos (fuente: DeCS, BIREME).

$\mathrm{O}$ interesse em elaborar um instrumento para avaliar a Qualidade de Vida(QV) dentro de uma expectativa legitimamente universal fez com que a Organização Mundial da Saúde desenvolvesse um projeto internacional, o Projeto WHOQOL (2). O resultado destes estudos foi a criação do WHOQOL-100, um instrumento de avaliação da QV composto por 100 itens(1). O cálculo dos resultados do WHOQOL-100 é realizado através de uma sintaxe desenvolvida pela OMS através do software estatístico Statistical Package for the Social Sciences (SPSS).

A utilização de um software específico para análise dos dados e a falta de documentos descrevendo este processo pode constituir uma restrição do protocolo do WHOQOL-100, de forma a inibir a utilização do instrumento.

O entendimento da sintaxe proposta pelo Grupo WHOQOL possibilita a análise dos dados ou o desenvolvimento de sintaxes em outros programas de análise estatística ou gerenciadores de base de dados que calculem índices de QV, melhorando o gerenciamento das informações. E, também, permite a análise parcial do instrumento, quando se deseja avaliar domínios ou facetas específicas.

Com base nessa perspectiva, o presente trabalho tem como objetivo descrever esta sintaxe, possibilitando o entendimento dos comandos e suas finalidades.

\section{SINTAXE PARAANÁLISE DOS DADOS DOWHOQOL-100}

A sintaxe foi desenvolvida pelo Grupo WHOQOL, para análise de dados através do software SPSS. Esta sintaxe é composta por 68 linhas (Figura 1) de comandos que serão descritas a seguir.

A primeira linha pauta-se em verificar se todas as questões foram preenchidas corretamente, com as respostas 1,2,3,4 ou 5. Caso contrário, a resposta ficará em branco e não será computada. 
Figura 1. Linha de comando para calcular o escore de uma faceta

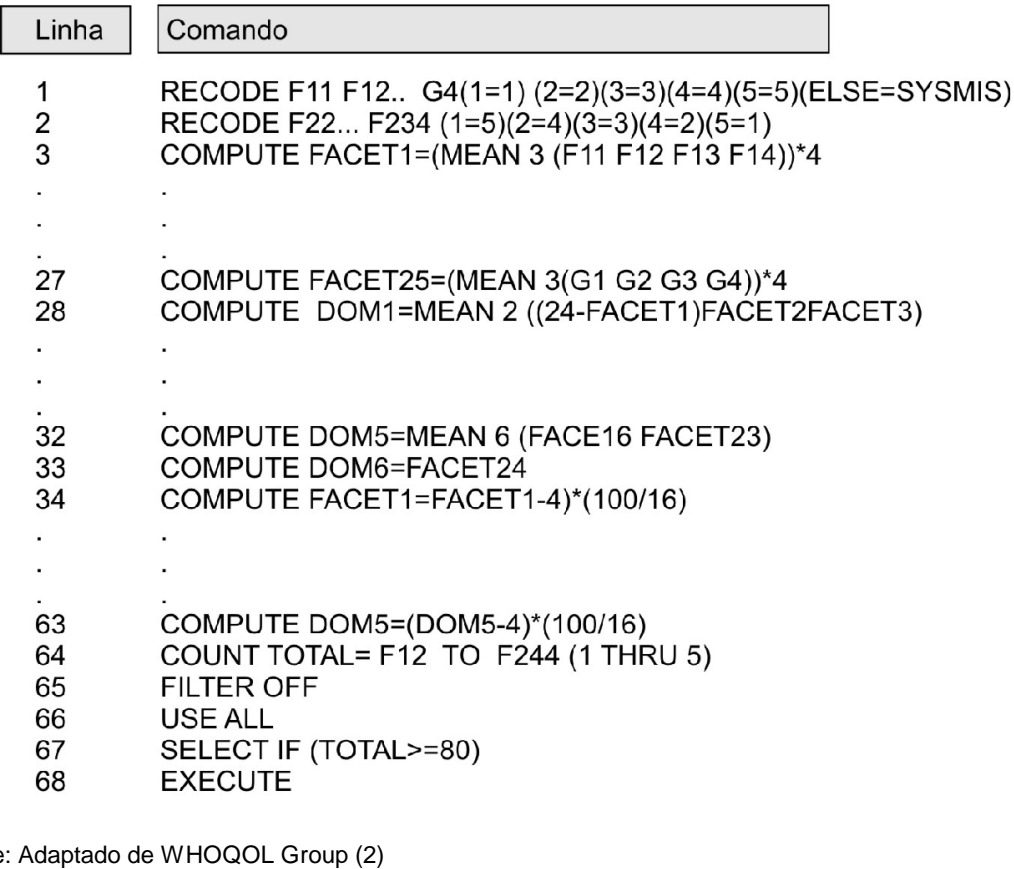

O WHOQOL-100 possui perguntas classificadas como negativas e positivas. Para o cálculo da média das facetas composta por questões com as duas categorias, deve-se considerar a leitura inversa da escala de Likert para as questões negativas. Este problema é tratado a partir da segunda linha de comando, que inverte as pontuações destas questões. Este comando pode ser substituído, em caso da utilização de outro software, pela equação matemática representada na Figura 2.

Prosseguindo a descrição dos comandos, da linha três à linha 27 são calculados os escores das facetas, dando origem a 25 novas colunas de resultados, correspondentes ao somatório de cada faceta. A pontuação de uma faceta corresponde à soma de quatro questões válidas Destas, duas questões avaliam um determinado aspecto e outras duas ponderam o quanto esses aspectos interferem na QV. 
Considerando-se a possibilidade da existência de questões não respondidas, esta sintaxe utiliza um comando (Figura 3) que garante o mínimo de três (75 $\%)$ das questões respondidas em cada faceta, descartando da análise as facetas que não atingirem esse valor. Assim, uma faceta é pontuada, somente se a mesma for avaliada e ponderada.

Este comando calcula a média entre o mínimo de três elementos válidos, que é quadruplicada dando origem ao escore da faceta. Desta forma, para casos onde o número de questões for menor de três elementos, não se gera o valor da faceta. E quando uma faceta for composta de por apenas 3 questões válidas, a questão invalida será equivalente à média entre as questões válidas.

Figura 2. Linha de comando para calcular o escore de uma faceta

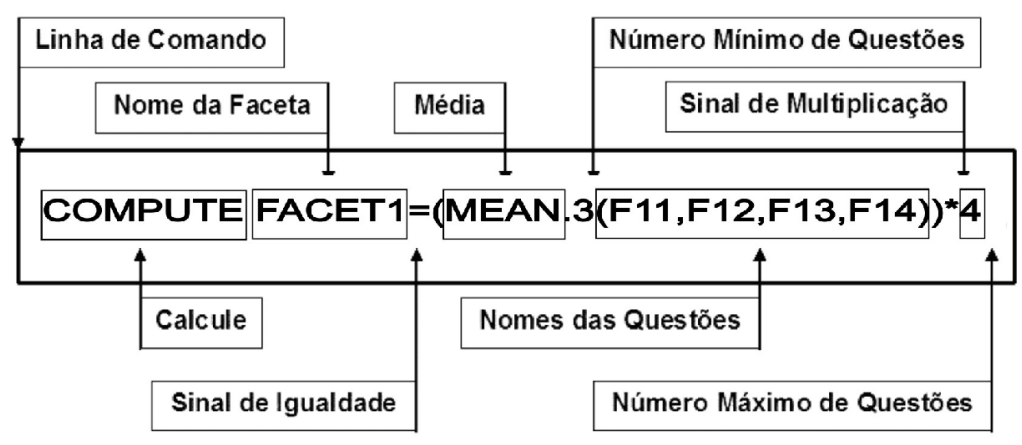

Figura 3. Equação para inversão de escala

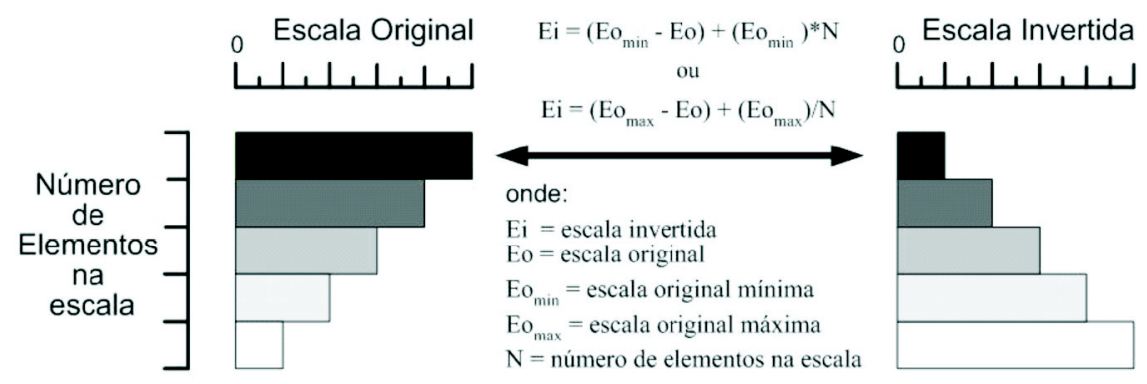

Os comandos das linhas 28 a 33 realizam o cálculo dos escores dos domínios, dando origem a seis novas colunas, correspondentes à média de cada domínio. A pontuação de um domínio corresponde à média de "n" facetas. Levando-se em conta, também, a possibilidade da existência de facetas com 
valores numéricos nulos, a sintaxe trata esses problemas nos domínios I,II,III e IV com a seguinte fórmula, inserida no comando "MEAN":(x -1). Onde "x" corresponde ao número de facetas do domínio. Este comando garante que o domínio somente será calculado se possuir no máximo uma faceta não pontuada. Para o domínio V, que contém o maior número de facetas, a sintaxe utiliza a seguinte fórmula no comando "MEAN":(x-2), que permite o máximo de duas facetas não pontuadas.

Como existem facetas negativas, compostas em sua totalidade por questões negativas, utiliza-se do seguinte artifício matemático: (24-FACET), que incorporado ao comando para calcular os escores desta facetas, inverte sua pontuação.

As linhas de comando de número 34 a 63 convertem os valores de uma escala contínua de 4 a 20 para uma escala centesimal, através de uma expressão equivalente à seguir:

$$
E D=i E D+(E D-i E O) x \frac{\Delta E D}{\Delta E O}
$$

Onde:

ED é escala desejada;

EO é escala original;

i é o inicio da escala;

$\Delta$ é a variação da escala

O comando da linha 64 gera uma coluna com o nome de "TOTAL", que contém a contagem de todas as questões com valores válidos.

Finalizando, as linhas de comando de 65 a 68 permitem computar apenas os questionários com pelo menos $80 \%$ dos itens preenchidos corretamente, eliminado da amostra os registros que não satisfazem tal condição.

\section{CONCLUSÃO}

A dificuldade em compreender a sintaxe dos instrumentos WHOQOL constitui um fator limitante na utilização destes instrumentos. Frente a este imbróglio, o presente estudo pauta-se em esclarecer o funcionamento da sintaxe do WHOQOL-100. 
Através da compreensão dos comandos e artifícios matemáticos utilizados na Sintaxe do SPSS para a análise dos dados do WHOQOL-100 é possível desenvolver a análise dos dados em outros softwares. $\mathrm{O}$ artifício possibilita $\mathrm{o}$ desenvolvimento completo ou parcial do instrumento, ou ainda, o enriquecimento da sintaxe original através da adição de outros comandos e, até mesmo, dispensar a utilização de softwares estatísticos.

Cada questão corresponde a um valor entre 1 e 5, cada faceta equivale ao somatório dos escores de quatro questões que constitui, por sua vez, os domínios, correspondentes à média entre suas facetas.

As facetas compostas por questões negativas e positivas, e também, os domínios compostos por facetas com esta característica, são tratados na sintaxe através de recursos matemáticos que possibilitam a inversão dos escores originais. Com efeito, é importante identificar as relações de dependência de proporções diretas ou inversas entre os atributos para evitar erros na análise dos dados

\section{REFERÊNCIAS}

1. Fox-Rushby J, Parker M. Culture and the measurement of health-related quality of life. Journal of European Applied Psychology1995;45(4):257-263.

2. The WHOQOL Group. WHOQOL Users Manual (draft). Geneva: World Health Organization;1998.

3. Fleck MPA, Leal OF, Louzada S, Xavier M, Chachamovich E, Vieira G, et al. Application of the portuguese version of the instrument for the assessment of the quality of life of the World Health Organization (WHOQOL-100). Revista Saúde Pública. 1999; $\mathrm{abr} ; 33(2): 198-205$. 